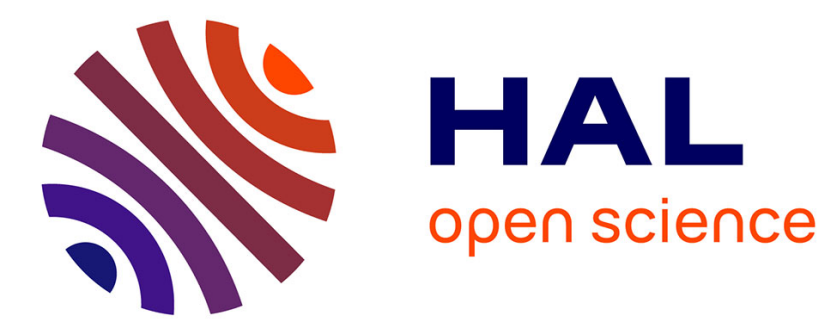

\title{
PROPERTIES OF THICK EVAPORATED LAYERS OF PbTe
}

C. Evans, J. Seeley

\section{To cite this version:}

C. Evans, J. Seeley. PROPERTIES OF THICK EVAPORATED LAYERS OF PbTe. Journal de Physique Colloques, 1968, 29 (C4), pp.C4-37-C4-42. 10.1051/jphyscol:1968405 . jpa-00213609

\section{HAL Id: jpa-00213609 https://hal.science/jpa-00213609}

Submitted on 1 Jan 1968

HAL is a multi-disciplinary open access archive for the deposit and dissemination of scientific research documents, whether they are published or not. The documents may come from teaching and research institutions in France or abroad, or from public or private research centers.
L'archive ouverte pluridisciplinaire HAL, est destinée au dépôt et à la diffusion de documents scientifiques de niveau recherche, publiés ou non, émanant des établissements d'enseignement et de recherche français ou étrangers, des laboratoires publics ou privés. 


\title{
PROPERTIES OF THICK EVAPORATED LAYERS OF PbTe (*)
}

\author{
C. S. Evans and J. S. Seeley \\ Department of Applied Physical Sciences, University of Reading, England
}

\begin{abstract}
Résumé. - La transparence optique des couches monocristallines de $\mathrm{PbTe}$ peut varier après un traitement thermique suivant l'évaporation. Les monocouches ont quelques microns d'épaisseur et le recuit fait décroître la densité de porteurs d'environ $10^{18} \mathrm{~cm}^{-3}$ (type $n$ ) à $10^{17} \mathrm{~cm}^{-3}:$ le matériau de la source est à $10^{1}{ }^{1} \mathrm{~cm}^{-3}$ (type $p$ ). Le processus semble faire intervenir la diffusion de $\mathrm{O}_{2}$ à un taux de réaction correspondant à une énergie de $0,83 \mathrm{eV}$.
\end{abstract}

\begin{abstract}
The changes in the optical transparency of $\mathrm{PbTe}$ monolayers induced by post-evaporation heat treatment are described. The monolayers are typically a few microns in thickness and heat treatment reduces the carrier density from about $10^{18}\left(n\right.$-type) per $\mathrm{cm}^{3}$ to $10^{17} \mathrm{per}^{3} \mathrm{~cm}^{3}$ : the source material is $10^{19}$ ( $p$-type) per $\mathrm{cm}^{3}$. The process seems to involve the diffusion of $\mathrm{O}_{2}$ at a reaction rate equivalent to an energy of $0.83 \mathrm{eV}$.
\end{abstract}

1. Introduction. - During a programme to develop multilayer filter techniques for the infrared [1] an intensive study has been made of the suitability of $\mathrm{PbTe}$ as a high-index material for filters for the region 5-25 $\mu$. The method of manufacturing these filters is essentially vacuum evaporation and, when depositing $\mathrm{PbTe}$ in alternating combination with a low-index material such as $\mathrm{ZnS}$, control of deposition temperature is most important [2]. On transferring the process into an evaporating unit in our laboratory we have found that optimum temperatures worked out by our collaborators for a different unit in a different laboratory do not necessarily enable us to reproduce the level of transparency they regularly attain. The main difficulty has been established as excessive absorption in our $\mathrm{PbTe}$ layers and we have further found that this can be reduced to an acceptable level by post-deposition heat treatment. Our further investigations into this effect have been concentrated on monolayers of $\mathrm{PbTe}$, deposited in various ways, and are described below.

2. Refractive index measurements. - The dispersion and absorption in $\mathrm{PbTe}$ due to the presence of carriers can be described by the following relations :

$$
\begin{aligned}
n^{2}-\kappa^{2} & =n_{0}^{2}-\frac{N e^{2}}{m^{*} \varepsilon_{0}} \cdot \frac{1}{\left(\omega^{2}+g^{2}\right)} \\
2 n \kappa & =\frac{\omega}{g} \cdot \frac{N e^{2}}{m^{*} \varepsilon_{0}} \cdot \frac{1}{\left(\omega^{2}+g^{2}\right)} .
\end{aligned}
$$

$\left(^{*}\right)$ This research has been sponsored in part through the European Office of Aerospace Research, OAR, United States Air Force under Contract AF 61(052)-833.
Where $n$-i $i$ is the complex refractive index of PbTe $n_{0}$ is the refractive index in the absence of carriers (determined by lattice vibration and interband transitions).

$N$ is the number of carriers per unit volume.

$\omega$ is frequency of incident radiation.

$g$ is a damping constant, equated to reciprocal mean free time between carrier collisions.

$m^{*}$ the susceptibility effective mass.

The $\mathrm{PbTe}$ is evaporated in an 18 inch Edwards unit by standard techniques onto temperature controlled substrates, and thickness is monitored by reflectance at $3.93 \mu$. A particular monolayer to be described was evaporated from an alumina crucible onto silicon held at $300^{\circ} \mathrm{C}$ and monitored as 12 quarter waves, or approximately $2 \mu$ physical thickness. Half the substrate was masked by molybdenum foil to give a sharp step at the edge of the film. The height of the step was determined in an interference microscope. Optical thicknesses were determined at certain specific wavelengths, by measuring the spectral transmission from $3 \mu$ to $25 \mu$ on a Grubb-Parsons Spectromaster. Figure 1 shows the transmission of the PbTe-coated silicon and for comparison the transmission of the uncoated half of the same substrate. For multiples of half-wave optical thickness, transmission is a maximum and in the absence of absorption or scattering would equal that of the uncoated substrate. For odd multiples of a quarter-wave optical thickness the transmission is a minimum. If the wavelength at transmission 


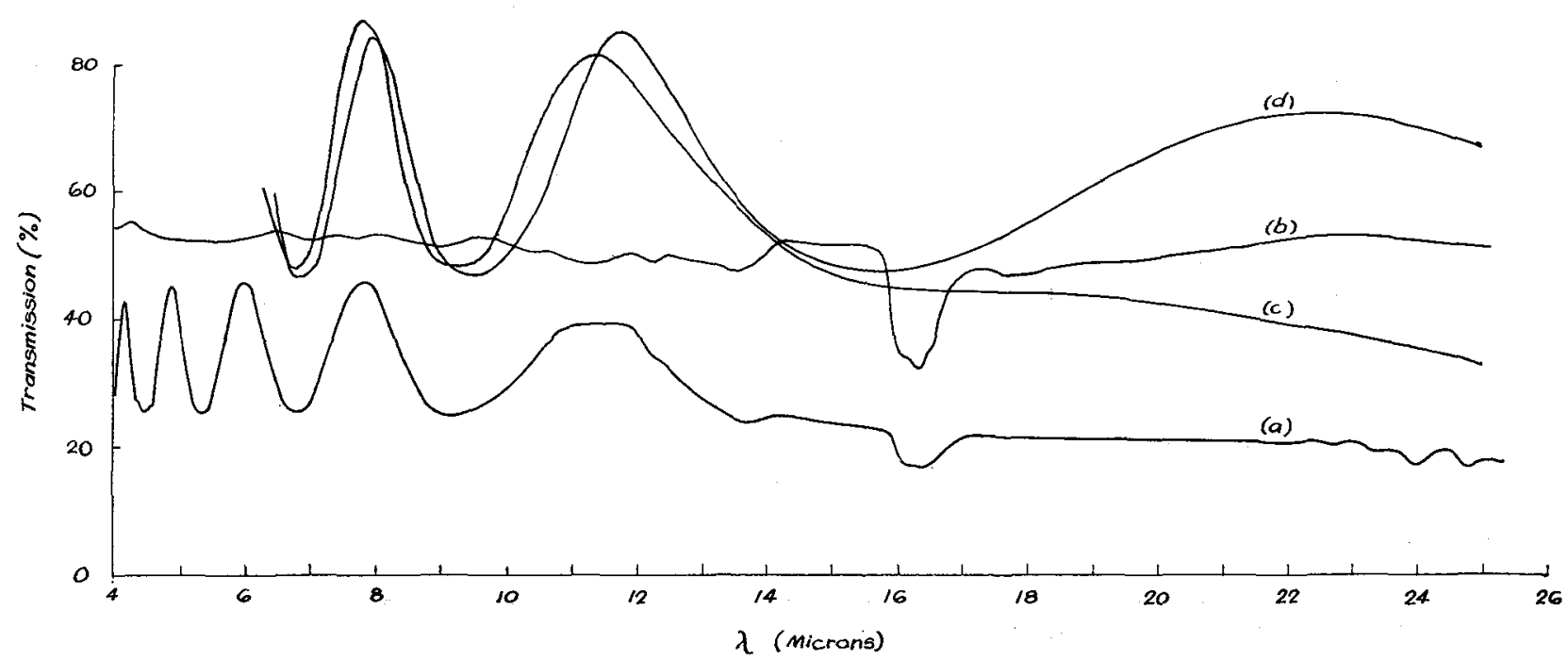

FIG. 1. - Transmission spectrum of PbTe monolayer (2.06 microns thick) on $\mathrm{Si}$. $-a$ ) Before heat treatment: $-b$ ) Substrate alone. - c) Ratio (a) : (b). - d) Ratio, after heat treatment.

extrema is $\lambda_{\mathrm{m}}$ then for a film on a semi-infinite substrate

$$
m \lambda_{\mathrm{m}}=n\left(\lambda_{m}\right) t+\beta_{1}+\beta_{2},
$$

(where $m$ is the integral interference order. $n\left(\lambda_{m}\right)$ is refractive index at $\lambda_{\mathrm{m}}: t$ is the thickness of the film. $\beta_{1}, \beta_{2}$ are phase changes on reflection at the film surface which become significant for large values of $\kappa$ ). In practice for a finite substrate, the contribution of $\kappa$ to the spectral position of the peak is estimated from computations at various $n$ and $\kappa$ values. The order of interference is allocated unambiguously from the deposition record, and the wavelength of the extrema can be measured to an accuracy limited principally by the fringe sharpness. This is much more accurate than the step height measurement. Thus values of index can be deduced at these wavelengths with an absolute accuracy of about $0.6 \%$ but relative accuracy of $0.2 \%$ or better.

The transmission of the film shows strong free carrier absorption at long waves; in the absence of absorption there would be a further (second order) peak at about $23 \mu$. Also at short waves there is some scattering which is not present under some deposition conditions. The monolayer transmittance is also shown as a ratio of the traces for coated and uncoated halves.

The sample was heated to $340^{\circ} \mathrm{C}$ in air for about 5 minutes, cooled and measured. For clarity the transmission trace is not shown but the ratio of coated to uncoated transmission is shown. There is a marked increase in transparency which could be due to an overall reduction in either carrier concentration, or in damping constant. In addition however there is a shift of all extrema to longer wavelengths. This is due to an increase in refractive indices and can only be explained by a reduction in the number of carriers.

To interpret the dispersion of this monolayer in terms of free carriers it is necessary to first determine the dispersion due to short wave interband absorption. For this purpose the spectral region shown can be split into two parts. The contribution of carriers decreases with $\lambda^{2}$ and at short wave is relatively small, thus below $8 \mu$ the index is largely determined by the interband transitions, and becomes highly dispersive near the absorbing region.

If this dispersion is considered as being due to a simple classical oscillator of resonant wavelength $\lambda_{0}$ then the index $n_{0}$ obeys the relation

$$
\frac{n_{\infty}^{2}-1}{n_{0}^{2}-1}=1-\frac{\lambda_{0}^{2}}{\lambda^{2}} \text {. }
$$

$n_{\infty}$ is an asymptotic value of the index $n_{0}$ at long wavelengths, $i$. e. the lattice contribution.

Walton and Moss [3] have measured the index of single crystals in the range $4.5 \mu$ to $8 \mu$. The samples had $10^{18}$ carriers per $\mathrm{cm}^{3}$ and their effect was considered negligible at these wavelengths. They found $n_{\infty}=5.64 \pm .03$ and $\lambda_{0}=1.27 \mu$.

At long wavelengths as $n_{0}$ approximates to $n_{\infty}$ the measured index $n$ is determined largely by the carriers according to relation (1), which for

$$
g^{2} \ll \omega^{2}, \quad \kappa^{2} \ll n^{2}
$$


becomes

$$
n^{2}=n_{0}^{2}-\frac{N e^{2}}{m^{*} \varepsilon_{0}} \cdot \frac{\lambda^{2}}{4 \pi^{2} c^{2}} .
$$

Thus plotting $n^{2}$ versus $\lambda^{2}$ should give a straight line, with slope yielding carrier concentration. In practice we did not have enough points at long wave to avoid the edge dispersion region. Using the indices found for the untreated sample a graph was plotted negligible in the treated sample, values of $n_{0}$ were read from the lower line and used in relation (5) and $n$ was calculated for various values of carrier concentration. An effective mass was inserted from values obtained optically for $n$-type crystals by Walton, Moss and Ellis [4] as the monolayers are believed to be $n$-type. Values for $p$-type crystals are not very different however $[5,6,7]$.

Figure 2 shows curves calculated for $n$ versus $\lambda$ for various carrier concentrations. Our experimental

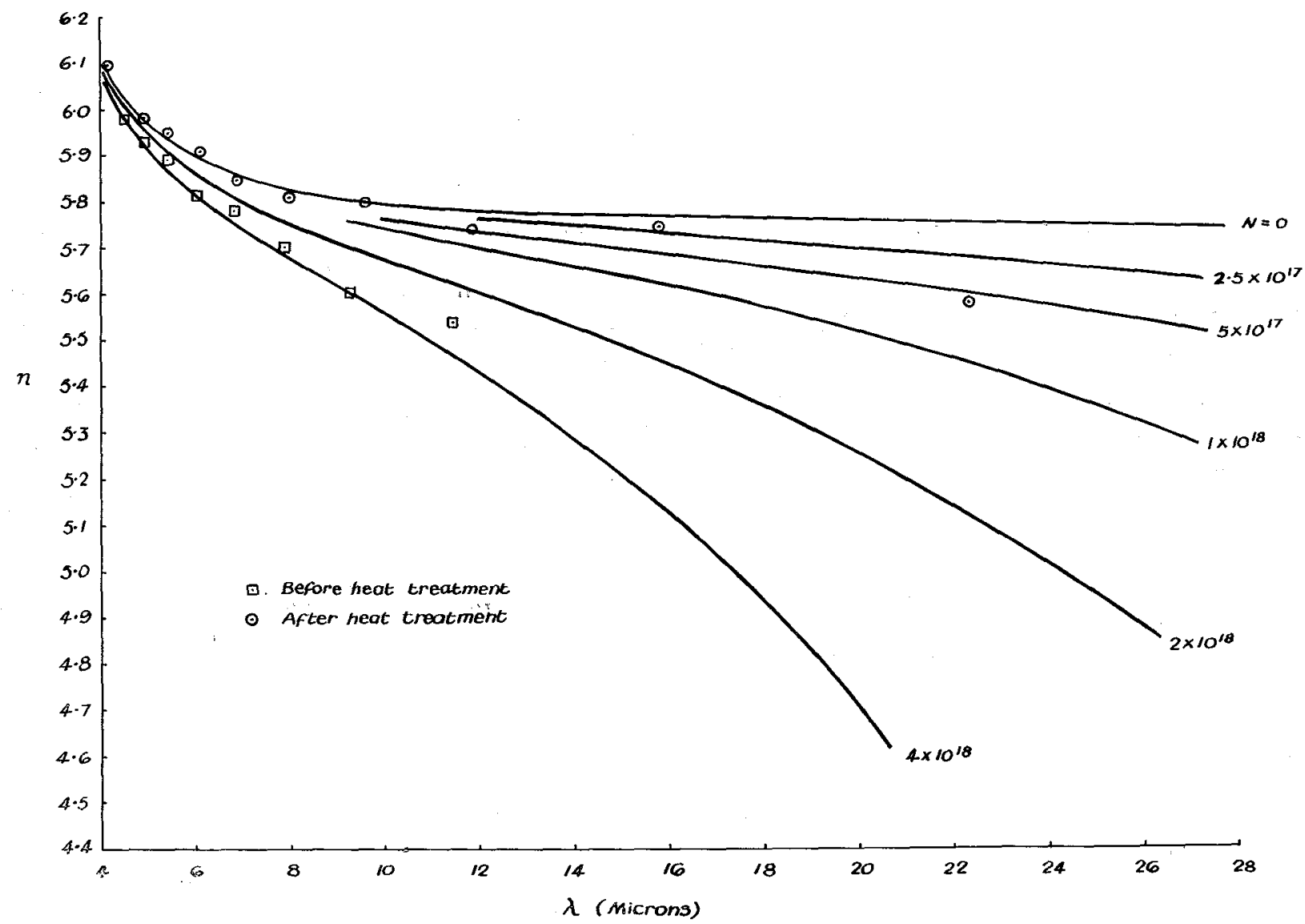

FIG. 2. - Dispersion curves for $\mathrm{PbTe}$.

of $\left(n^{2}-1\right)^{-1}$ versus $\lambda^{-2}$ (Fig. 3). Within the limits of error a straight line can be fitted to all but 3 long wave points. The same function is plotted for the index of the sample after heat-treatment, the lower line. Extrapolating, $n_{\infty}$ is obtained together with intermediate indices. It is clear from the separation of these two lines that for the untreated sample at least, carrier effects are significant. At high concentrations the locus is asymptotic to the straight line; even in the untreated sample there is some deviation at long waves. To test the approximation that carrier effects are values of index are plotted also. It is evident from the fit at long waves that after heat treatment carrier concentration is less than $5 \times 10^{17}$ per $\mathrm{cm}^{3}$; this concentration affects the measured index by approximately $-0.25 \%$ at $10 \mu,-0.13 \%$ at $8 \mu$, and can be neglected below $8 \mu$. Thus the extrapolation for the heat-treated sample is not significantly in error and yields the results

$$
\begin{aligned}
& n_{\infty}=5.74 \pm .03 \\
& \lambda_{0}=1.379( \pm .007) \mu
\end{aligned}
$$




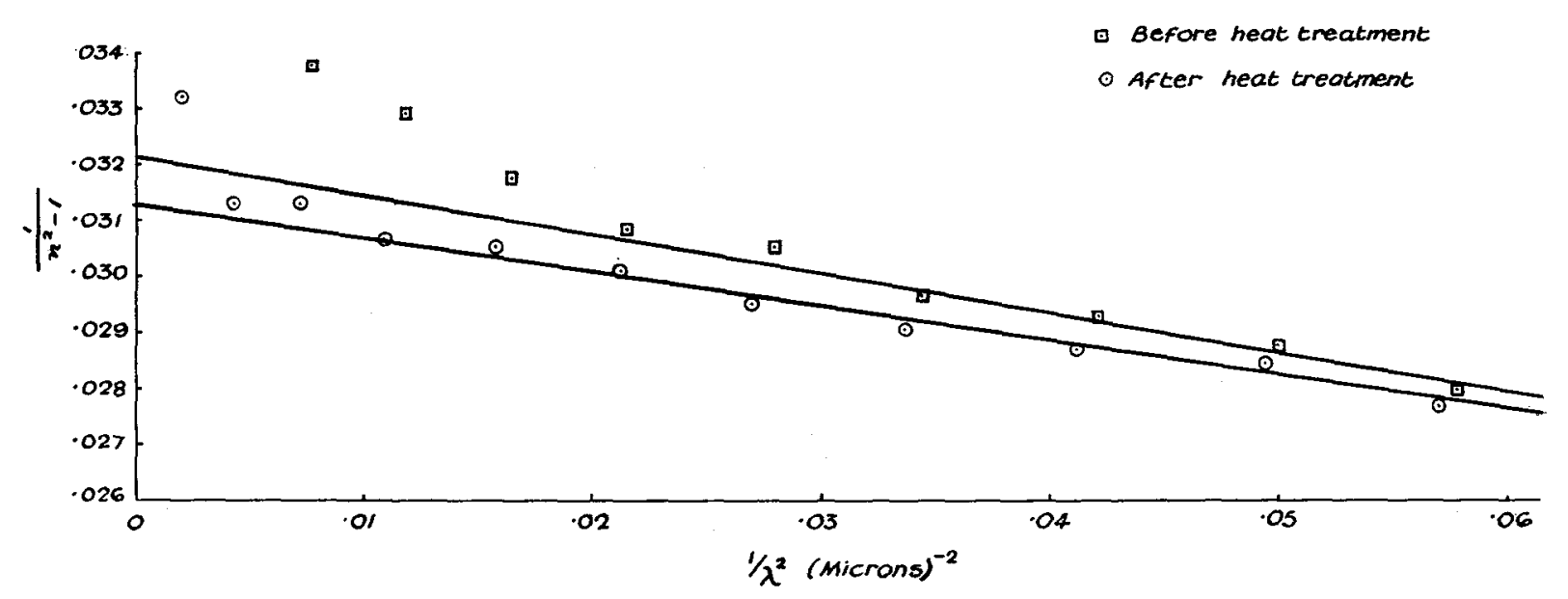

FIG. 3. - Extrapolation to obtain $n_{\infty}$.

The fit in figure 3 yields the following carrier concentrations

$$
\begin{aligned}
& \text { Before treatment } 4 \times 10^{18} \text { per cm } \mathrm{cm}^{3}\left( \pm 1 \times 10^{18}\right) \\
& \text { After treatment } 3 \times 10^{17} \text { per } \mathrm{cm}^{3}\left( \pm 1 \times 10^{17}\right)
\end{aligned}
$$

The curves show the effect of $4 \times 10^{18}$ carriers per $\mathrm{cm}^{3}$ is significant even at $4 \mu$, and to deduce the form of the edge dispersion in a sample with this order of doping some re-iterative correction for carriers is necessary.

It is concluded then that the heat-treatment reduced carrier concentration by roughly a factor of 10 .

Absorption indices can only be estimated to be between wide limits in this monolayer, and others on silicon, owing to a consistent loss of transmission throughout the wavelength range. This appears to be wavelength independent and does not occur on germanium substrates. Greater precision in determining $\kappa$, and hence the damping constant, should be possible using germanium. For this monolayer on silicon it cannot be concluded whether the damping increases or decreases on heat treatment.

Analysis of the dispersion of other monolayers has yielded carrier concentrations spread between $7 \times 10^{17}$ per $\mathrm{cm}^{3}$ and $4 \times 10^{18}$ per $\mathrm{cm}^{3}$, before heat treatment. In some cases damping constant can be estimated revealing a wide spread in this parameter. For example two films of $2 \mu$ thickness, deposited on $\mathrm{Si}$ at $300^{\circ} \mathrm{C}$ from two different types of source revealed the following estimates

$\begin{array}{ccc}\text { Source } & N & g \\ \text { Alumina } & & \\ \text { crucible } & 7 \times 10^{17} \text { per cm } & \omega \simeq g \text { at } \lambda=25 \mu \\ \text { Ta boat } & 3 \times 10^{18} \text { per cm }^{3} & \omega^{2} \gg g^{2} \text { at } \lambda=56 \mu\end{array}$

In the first case the free carrier dispersion was found to be anomalous at $24 \mu$, as compared with its trend up to $10 \mu$, in a manner which can only be explained if $g$ is comparable with $\omega$. In the second case there was no such index anomaly up to $56 \mu$ at least.

3. The heat treatment process. - Experiments have been performed to observe both the shift and increase in extrema as functions of time during the heat treatment process. Samples were heated for a short interval, cooled and measured and the cycle repeated to obtain time and temperature dependent behaviour. The process is found to be exponential with time and the limiting time is itself an exponential function of temperature (characteristic of a rate process). An approximate fit is obtained to a relation of the form

$$
t=A \cdot \exp \left(\frac{E_{\mathrm{w}}}{k T}\right)
$$

where $E_{w}=0.83 \mathrm{eV}$.

For instance, for samples heated at $320^{\circ} \mathrm{C}$, no further change could be observed after about 10 minutes at atmospheric pressure; whereas at $270^{\circ} \mathrm{C}$ the corresponding time is 3 hours. Scanlon [8] reports studies on the heat treatment of PbTe crystals with excesses of $\mathrm{Pb}$ and $\mathrm{Te}$. Such excesses are believed to exist as interstitial atoms which can be diffused out and precipitated at dislocations or grain boundaries by annealing. However, the rates involved are different by orders of magnitude : Scanlon's results for $n$-type $\mathrm{PbTe}$ rich in $\mathrm{Pb}$ show a time of 50 hours is required at $400^{\circ} \mathrm{C}$ to reduce carrier concentration from $7.8 \times 10^{17}$ per $\mathrm{cm}^{3}$ to $2.5 \times 10^{17}$ electrons $/ \mathrm{cm}^{3}$. In $p$-type $\mathrm{PbTe}$ rich in Te a sample of $10^{18}$ carriers per $\mathrm{cm}^{3}$ heated at $294^{\circ} \mathrm{C}$ reached an equilibrium value 
of $4.8 \times 10^{17}$ carriers per $\mathrm{cm}^{3}$ after 40 hours, and he reports similar results are obtained in vacuo, or air.

Our heat treatment, for evaporated thick films, is found to require the presence of oxygen. Similar effects are observed at reduced pressures if heating is continued for several days but it is not clear whether this is a different process or the same one at reduced rate due to reduced oxygen pressure.

4. Discussion. - Table 1 summarises some other measurements which have been made on the monolayers, including in the first row the dispersion results discussed above. and could evaporate faster and may re-evaporate from the heated substrate. For a vapour pressure of $10^{-5}$ torr $\mathrm{Pb}$ requires $485^{\circ} \mathrm{C}$ and $\mathrm{Te} 242^{\circ} \mathrm{C}$ [11]). So far, no significant difference in transparency has been found between monolayers deposited successively from the same source charge.

Experiments have been performed to compare the effect of different substrate temperatures under otherwise similar conditions, depositing on germanium. Differences were found at $300^{\circ} \mathrm{C}, 200^{\circ} \mathrm{C}$ and $100^{\circ} \mathrm{C}$ with respect to longwave transparency, the best result being at $200^{\circ} \mathrm{C}$, and the worst at $300^{\circ} \mathrm{C}$, but the differences were slight when compared with the effects of

TABLE I

Parameters of PbTe monolayers.

\begin{tabular}{|c|c|c|c|c|c|c|}
\hline Sample & Measurement & $\begin{array}{c}\text { Heat } \\
\text { treatment }\end{array}$ & $\begin{array}{c}\text { No. of } \\
\text { carriers } \\
\text { per } \mathrm{cm}^{3}, N\end{array}$ & $\begin{array}{l}\text { Type of } \\
\text { carrier }\end{array}$ & $\begin{array}{c}\text { Damping } \\
\text { constant, } \\
g, \sec ^{-1}\end{array}$ & $\frac{g}{N}, \mathrm{~cm}^{3} \mathrm{sec}^{-1}$ \\
\hline 2.06 microns, & Dispersion & Before & $4 \times 10^{18}$ & - & $(4.2-1.5) \times 10^{12}$ & \\
\hline on $\mathrm{Si}$ & & After & $3 \times 10^{17}$ & - & - & \\
\hline $\begin{array}{l}\sim 4 \text { microns, } \\
\text { on } \mathrm{Ge}\end{array}$ & Faraday $\left({ }^{1}\right)$ & - & $4 \times 10^{18}$ & $\mathrm{n}$ & - & \\
\hline $\begin{array}{c}\sim 2 \text { microns } \\
\text { on } \mathrm{Ge}\end{array}$ & Plasma $\left({ }^{3}\right)$ & - & $1 \times 10^{18}$ & - & - & \\
\hline$\sim 1$ micron, & Resistivity $\left({ }^{2}\right)$ & Before & & - & & $3.6 \times 10^{-5}$ \\
\hline $\begin{array}{l}\text { on fused } \\
\text { quartz }\end{array}$ & & After & & - & & $1.8 \times 10^{-2}$ \\
\hline $\begin{array}{l}\sim 2 \text { microns, } \\
\text { on glass }\end{array}$ & Hall $\left({ }^{2}\right)$ & - & $4 \times 10^{16}$ & $\mathrm{n}$ & $8 \times 10^{13}$ & \\
\hline $\begin{array}{l}\text { Source material } \\
\text { (granules), prior } \\
\text { to evaporation }\end{array}$ & Seebeck $\left({ }^{4}\right)$ & - & $10^{19}$ & $\mathrm{p}$ & - & \\
\hline
\end{tabular}

With regard to the source material, the purity of the $\mathrm{Pb}$ used is $99.9999 \%$, and the Te $99.999 \%$ containing not more than 10 parts per million of Se. The materials are weighed [9] before granulation in stoichiometric proportions to 1 part in $10^{5}$. It can be inferred that the concentration of $10^{19} p$-type carriers arises by crystals solidifying out with excess $\mathrm{Te}$ in their lattices, with free $\mathrm{Pb}$ solidified external to the lattice. Phase diagrams [10] suggest this is likely.

It is possible that such an excess of $\mathrm{Te}$ could be altered to an excess of $\mathrm{Pb}$ in the evaporation and deposition of the material, owing to the different vapour pressures of $\mathrm{Pb}, \mathrm{Te}$ and $\mathrm{PbTe}$, ( $\mathrm{Te}$ is the most volatile different source arrangements and different substrates.

A simultaneous deposition on $\mathrm{Si}$, Si with a thin $\mathrm{ZnS}$ layer, $\mathrm{Ge}$ and $\mathrm{Ge}$ with a thin $\mathrm{ZnS}$ layer, at $300^{\circ} \mathrm{C}$ produced marked differences in transparency. The worst result was on Si and was accompanied by a microscopic mosaic of cracks in the PbTe layer at spacings between 10 and $50 \mu$. The transparency was improved on both $\mathrm{Ge}$ and $\mathrm{Si}$ by the presence of $\mathrm{ZnS}$, correlated with a reduction in the extent of the cracking. (The cracking may arise from mismatch of thermal expansions, which is greatest in $\mathrm{Si}$ and least in $\mathrm{ZnS}$. Whether it is accompanied by smaller scale defects which can affect carrier mobilities is a matter of conjecture). 
Equally significant differences in transparency have been found in depositing onto $\mathrm{Si}$ at $300^{\circ} \mathrm{C}$ from various types of source. Indirectly-heated alumina crucibles and quartz dishes give markedly better results than Mo or $\mathrm{Ta}$ resistance-heated boats. It appears in fact that heat treatment of the boat-produced layers yields transparency roughly equal to that of untreated crucible-produced films. Furthermore in one case an evaporation from a shallow dish of quartz produced a monolayer of the highest transparency which was slightly degraded on heat treatment with spectral shift to shorter wavelengths, indicating a tendency towards increase of carriers.

It will be evident that there is still some difficulty in producing consistently transparent monolayers of $\mathrm{PbTe}$ but measurement of carrier properties is providing some clues to achieving this.

Acknowledgements. - This study arose out of a series of suggestions by Dr. S. D. Smith during his conduct of the larger programme under USAF Contract AF 61 (052-833). We are grateful for many facilities subsequently extended by Dr. Smith and his group in the Physics Department of the University, and to our collaborators, Mr. H. A. Macleod and Mr. F. Ritchie of Grubb Parsons, Newcastle-uponTyne.

Most of the depositions were carried out by Mr. R. Hunneman.

\section{References}

[1] U. S. A. F. Contract AF61 (052)-833-Final Report, May 1968.

[2] RITCHE (F.), Unpublished work for University of Reading Thesis.

[3] Walton (A. K.) and Moss (T. S.), Proc. Phys. Soc., 1963, 81, 509.

[4] Walton (A. K.), Moss (T. S.) and Ellis (B.), Proc. Phys. Soc., 1962, 79, 1065.

[5] Dixon (J. R.) and Riedl (H. R.), Phys. Rev., 1965, 138, No 3A, 873.

[6] Iyden (H. A.), Phys. Rev., 1964, 135, No 2A, 514.

[7] Strices (P. J.), Burstein (E.) and Langenburg (D. N.), Phys. Rev. Letters, 1962, 9, 257.

[8] Scanlon (W. W.), Phys. Rev., 1962, 126, No 2, 509.

[9] Áвbott (C. E.), (Mining and Chemical Products Ltd) Private Communication.

[10] Strauss (A. J.), Transaction of the Metallurgical Society of AIME, 1968, 242, 354.

[11] Review (R. C. A.), December 1962, 574. 